\title{
Learning Curve and One-Year Outcome of XEN 45 Gel Stent Implantation in a Swedish Population
}

This article was published in the following Dove Press journal:

Clinical Ophthalmology

\author{
Tobias Busch (D) \\ Dragana Skiljic (D) ${ }^{1,2}$ \\ Thiemo Rudolph' \\ Anders Bergström ${ }^{1,3}$ \\ Madeleine Zetterberg ${ }^{1,2}$ \\ 'Department of Ophthalmology, Region \\ Västra Götaland, Sahlgrenska University \\ Hospital, Mölndal, Sweden; ${ }^{2}$ Department \\ of Clinical Neuroscience, Institute of \\ Neuroscience and Physiology, \\ Sahlgrenska Academy, University of \\ Gothenburg, Gothenburg, Sweden; \\ ${ }^{3}$ Department of Ophthalmology, Skåne \\ University Hospital, Lund, Sweden
}

Purpose: Evaluation of 1-year-outcome of XEN 45 gel stent surgery in a Swedish cohort with regard to clinical success, complications, and learning curve.

Patients and Methods: This was a retrospective study of glaucoma patients undergoing glaucoma XEN-stent surgery alone or combined with phacoemulsification between December 2015 and May 2017. Intraocular pressure (IOP), number of medical agents, and adverse events were assessed. Clinical success rate was defined as achieving individual target pressure with/without medication.

Results: A total of 113 eyes were included in the final statistics. Mean age was $70.8 \pm 11.8$ years. Primary open angle glaucoma (POAG) accounted for $46.9 \%$ and exfoliative glaucoma (PEXG) for $40.7 \%$. Mean preoperative IOP was $23.8 \pm 6.2 \mathrm{mmHg}$ and mean number of agents 3.4. After 1 year, mean IOP was reduced to $16.1 \pm 4.7 \mathrm{mmHg}$ and medication to 1.34 substances on average. Failure rate at 1-year follow-up was $34 \%$ with no significant difference between POAG and PEXG. There was a trend of higher success rate for combined cases $(P=0.116)$. Stents with malpositioned or curved appearance had significantly worse outcome. The failure rate of the most productive surgeon dropped from $33 \%$ to $10 \%$ from the first implantations. Temporary hypotony $(19.5 \%)$ and choroidal detachment $(9.7 \%)$ were the most common complications. Blockage of the inner stent lumen was common (8.8\%), with a high proportion of failure.

Conclusion: XEN-stent surgery is a surgical option in uncontrolled glaucoma in both POAG and PEXG. A XEN-stent can reduce both IOP and the number of antiglaucoma medications needed. The learning curve is significant and stent positioning is crucial for optimal results. Combined XEN-cataract surgery is not inferior to stand-alone procedures. The long-time effectiveness is still to be proven.

Keywords: glaucoma, minimal invasive glaucoma surgery, MIGS, pseudoexfoliative glaucoma, XEN 45 gel stent, Ab interno implant, surgical success

\section{Introduction}

The XEN 45 gel stent was introduced to the European market in 2016. It creates a new outflow facility for aqueous humor from the anterior chamber to the subconjunctival space. The mechanism of action is therefore comparable with traditional trabeculectomy. Possible advantages compared with trabeculectomy could be shorter surgery time, standardized penetration of the sclera, and minor trauma to the eye, as neither conjunctival incisions, suturing, or iridectomy are required. The XEN 45 gel stent is indicated for the management of refractory glaucoma as a stand-alone procedure or in combination with cataract surgery. The procedure fulfils the criteria for minimal invasive glaucoma surgery (MIGS). ${ }^{1}$
Department of Ophthalmology, Region

Västra Götaland, Sahlgrenska University

Hospital, SE-43I 80, Mölndal, Sweden

Tel +460313421000

$\mathrm{Fax}+46031412904$

Email tobias.busch@vgregion.se 
There are as yet no randomized clinical trials concerning XEN implantation and long-term follow-up studies are scarce and limited to 3 years to the best of our knowledge. ${ }^{2,3}$ However, up to 5 years outcomes are reported concerning previous versions of the stent. ${ }^{4}$ Furthermore, results from a Scandinavian population with a high proportion of pseudoexfoliative glaucoma (PEXG) is lacking. The purpose of the present study was to describe the 1-year outcome of a Swedish cohort with regard to success in controlling intraocular pressure (IOP) with or without pharmacologic treatment. In addition, this study aimed to investigate the possible impact of type of glaucoma, PEXG vs POAG (primary open-angle glaucoma), lens status (pseudophakia/phakia), stand-alone procedure vs combination with cataract surgery, positioning of the stent, and also the learning curve for implantation of a XEN 45 gel stent as well as possible complications.

\section{Materials and Methods Study Design}

Implantation with a XEN 45 gel stent was introduced at the Department of Ophthalmology, Sahlgrenska University Hospital, Mölndal, Sweden, in December 2015. This is a tertiary referral center and university clinic and one of the first Swedish sites to adopt the procedure. A retrospective study was performed including all patients from the introduction of this technique until May 2017. The latter time point was chosen in order to ensure a 1-year follow-up period as a minimum. The study was approved by The Regional Ethical Review Board in Gothenburg and conducted in accordance with the tenets of the Declaration of Helsinki. Since this was a retrospective study, no consent was required from the subjects, according to the policy of the Regional Ethical Review Board. Data accessed complied with relevant data privacy and protection regulations.

Patients were offered XEN 45 gel stent implantation if suitable as assessed by the surgeon. Indications for surgery were either uncontrolled intraocular pressure (IOP), intolerance to anti-glaucoma drugs, progression of visual field defects, or a combination of the factors mentioned above. There were no limitations concerning preoperative level of IOP, grade of visual field defect, or type of glaucoma. Eyes with previous filtrating glaucoma surgery including previous failed XEN surgery were excluded from analysis. In the case of bilateral implantation, both eyes were included.

\section{Surgical Technique}

The data comprises the result of surgery performed by four anterior segment surgeons, none of whom had any previous experience of the XEN 45 gel stent. The surgery was performed either as a stand-alone procedure or in combination with cataract surgery. Some patients received preservativefree dexamethasone a week prior to surgery, but the majority of patients did not. Preoperative miosis was achieved by pilocarpine $2 \%$ eye drops (Trimb Healthcare AB, Stockholm, Sweden) for stand-alone procedures. If the procedure was combined with cataract surgery, the pupil was instead dilated with a combination of topical cyclopentolate $0.85 \%+$ phenylephrine $1.5 \%$ (extempore, APL, Stockholm, Sweden). In the event of combined surgery, standard phacoemulsification with implantation of an intraocular lens (IOL) was performed first, after which mydriasis was converted to miosis by intracameral acetylcholine chloride, $10 \mathrm{mg} / \mathrm{mL}$ (Miochol- ${ }^{\circledR}$, Bausch\&Lomb Nordic AB, Stockholm, Sweden). Standard preoperative preparation was performed including local anesthesia with topical tetracaine $(1 \%)$ (Tetracaine, Bausch\&Lomb Nordic AB, Stockholm, Sweden), rinsing of the conjunctival sac with chlorhexidine cutan solution $0.5 \mathrm{mg} / \mathrm{mL}$ (Fresenius Kabi AB, Uppsala, Sweden), and sterile draping. The conjunctiva in the upper nasal quadrant was hydrodissected by injection of $0.1 \mathrm{~mL}$ Mitomycin C $0.2 \mathrm{mg} / \mathrm{mL}$ or 5-Fluorouracile $50 \mathrm{mg} / \mathrm{mL}$ (extempore, Apoteket AB, Stockholm, Sweden). A peripheral corneal incision $1.2 \mathrm{~mm}$ wide was made nasally for later insertion of a counter-traction Vera Hook (a1 medical GmbH, Radolfzell am Bodensee, Germany). The main incision of $1.8 \mathrm{~mm}$ width was placed as a peripheral corneal tunnel in the temporal inferior quadrant. The anterior chamber was infused with xylocaine $10 \mathrm{mg} / \mathrm{mL}$ (Aspen Nordic, Ballerup, Denmark) and then filled with ocular viscoelastic device Healon GV (Johnson \& Johnson Vision, Uppsala, Sweden). The $\mathrm{XEN}^{\circledR} 45 \mathrm{Gel}$ Stent, preloaded into a $\mathrm{XEN}^{\circledR}$ Injector (Allergan plc, Dublin, Ireland), was advanced through the anterior chamber, trabecular meshwork, and sclera. The XEN 45 gel stent was then released into the subconjunctival or subtenonal space. If unproperly positioned, further manipulations were performed to optimize positioning, ie, explantation and reloading of the stent, or grasping the stent with forceps for manipulation of the stent through the intact conjunctiva. Intracameral cefuroxime (Aprokam ${ }^{\circledR}$ Laboratoires Théa, Clermont-Ferrand, France) was instilled in the anterior chamber at the end of the procedure. 
Postoperatively, all topical and systemic (acetazolamide; Diamox ${ }^{\circledR}$, Amdipharm Ltd, London, UK) anti-glaucomatous drugs were suspended, and anti-inflammatory topical therapy initiated with preservative-free dexamethasone $1 \mathrm{mg} / \mathrm{mL}$ (Dexafree ${ }^{\circledR}$, Laboratoires Théa, Clermont-Ferrand, France) 6-8 times/day. Depending on individual assessment, dexamethasone drops were tapered during a period of at least 2 months. Typically, follow-ups were scheduled at day 1 and after 1, 2, 3, 4, 6, and 8 weeks, with individual adjustments. In the case of encapsulation or fibrosis, needling procedures were performed in order to cut adhesions between sclera and conjunctiva.

\section{Analysis of Data}

Baseline data included age at surgery, sex, type, and duration of glaucoma diagnosis, average intraocular pressure at the last three preoperative measurements, number of antiglaucoma agents, and dosage of oral acetazolamide. Postoperative IOP at week 1, 2, 3 plus month 1, 2, 3, 6, and 12 were retrieved from medical records. Adverse events and need for interventions, ie, needling or additional surgery, were also noted.

Primary outcome in the present study was clinical success rate, either complete or partial success. Complete success was defined as the patient's individual target pressure (TP) achieved at month 12 without any medical treatment. If no target pressure was given in the medical journal, it was set to $20 \mathrm{mmHg}$. Partial success was defined as attained TP with the help of IOP-lowering pharmacologic treatment. Finally, surgery was classified as failure if IOP at the 1-year follow-up was above TP with/without medication, or if additional glaucoma surgery was performed under the study period, or if the XEN stent was obviously non-functioning, ie, broken or without physical connection with the anterior chamber, or if visual acuity was only light perception or worse after the surgery. Secondary outcomes were absolute reduction in IOP $(\mathrm{mmHg})$, relative reduction in IOP $(\%)$, and the reduction of number of IOL-lowering agents from baseline to month 12. Additional secondary outcomes were adverse events.

\section{Statistical Procedures}

Mean \pm standard deviation (SD) or proportions (\%) are given. For outcome at 1-year follow-up, Chi-square test or one-way analysis of variance (ANOVA) with Dunnett's post hoc test were used. For multiple comparisons Bonferroni correction was performed. Survival plots based on Kaplan-Meier estimates were generated for cumulative survival (probability of clinical success) and Cox proportional hazard ratio calculated. A $P<0.05$ was considered statistically significant.

\section{Results}

During the study period, 139 XEN 45 gel stents were implanted. Of these, 20 eyes were excluded because of previous glaucoma surgery. Six additional eyes were excluded due to incomplete data or because the subject was deceased. The remaining 113 eyes (Figure 1) were enrolled in the following statistical analyses. None of these eyes had undergone previous ocular surgery other than cataract.

\section{Descriptive Demographics at Baseline}

The most common indication for surgery was uncontrolled IOP $(n=70)$, intolerance to medication $(n=37)$, and progression of visual field defects $(\mathrm{n}=18)$, several different indications might coexist in the same patient. At the time of surgery, the average age was $70.8 \pm 11.8$ years. Gender was almost equally distributed. The vast majority of cases were either classified as POAG (46.9\%) or PEXG (40.7\%). Other types of glaucoma were rare, including: secondary glaucoma after IOL-luxation, iridocyclitis, goniodysplastic glaucoma, previous angle closure glaucoma, venous stasis glaucoma, and pigment dispersion glaucoma. The average duration of glaucoma prior to surgery was $9.7 \pm 8.5$ years (Table 1 ). Mean preoperative IOP was $23.8 \mathrm{mmHg}$, ranging from $12.3-40.0 \mathrm{mmHg}$, and the average number of pharmacologic IOP-lowering substances prior to surgery was 3.4. At baseline, 59 eyes (52\%) were pseudophakic. Antifibrotic agents were used in all cases; Mitomycin C in $95.6 \%$ and 5-Fluorouracil in $4.4 \%$ of patients. In 14 patients both eyes were operated on and included in the study. In 12 eyes the target IOP was defined as lower than $20 \mathrm{mmHg}$ (average $=15$ $\mathrm{mmHg}$, range $=12-18 \mathrm{mmHg}$ ). Overall for the complete cohort, the average target IOP was $19.5 \mathrm{mmHg}$.

\section{Outcomes}

A survival plot based on Kaplan-Meier estimates is shown in Figure 2A. Seven stents (6\%) never came into function due to malpositioning or intraoperative damage, and at 1 month, 19 stents (17\%) were classified as already failed. In 24 eyes (21\%), other types of secondary surgical glaucoma interventions were performed during the study period: If the first XEN stent was considered malpositioned, a second XEN stent could be favored $(n=8)$. Otherwise, trabeculectomy $(n=9)$, Ahmed shunt $(n=3)$, or diodelaser $(n=3)$ were utilized. For one patient, the type of procedure could not be retrieved. 


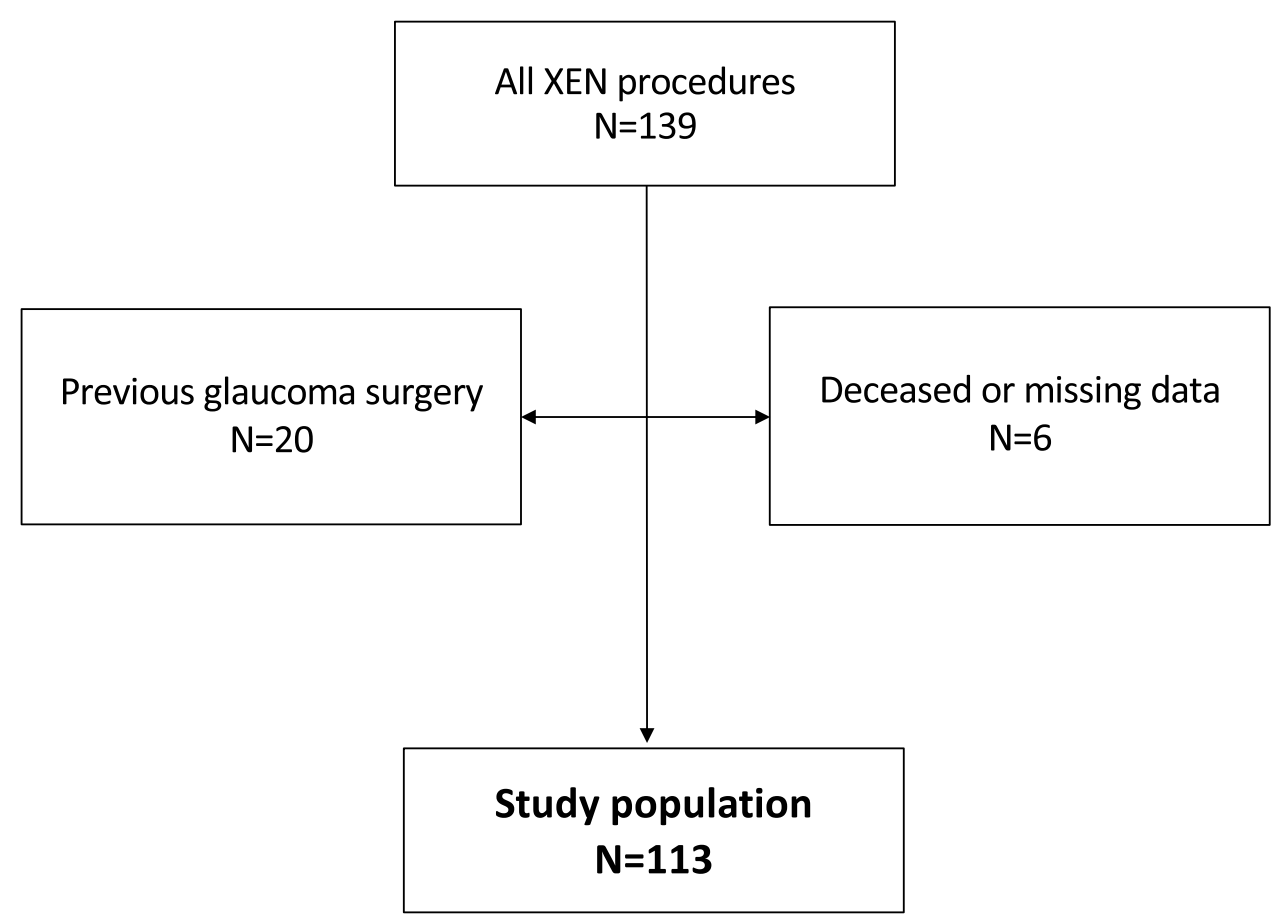

Figure I Flow chart describing study population. Patients with previous glaucoma surgery $(n=20)$, missing data or deceased subjects $(n=6)$ were excluded.

At 12 months, the clinical success rate was 64\% (31\% complete, $33 \%$ partial success), and the failure rate was $36 \%$ (Figure 2B).

In order to give better comparability to other published data, data are also presented at different IOP levels as well as combined criteria of obtained IOP and at least $20 \%$ reduction from baseline (Table 2).

On average, IOP decreased immediately postoperatively, despite all medication being paused, to 10.4 mmHg day $1,13.0 \mathrm{mmHg}$ week 1 , then stabilizing around $17 \mathrm{mmHg}$ (Figure 3). For those individuals who did not undergo additional glaucoma surgery during the study period $(\mathrm{n}=86)$, mean IOP preoperatively was $22.9 \pm 5.5$ $\mathrm{mmHg}$ and at 1-year follow-up, IOP was $16.1 \pm 4.7$ mmHg. Mean reduction in IOP during the study period was $6.8 \pm 6.5 \mathrm{mmHg}, P<0.001$ (paired $t$-test), ie, a $30 \%$ decrease in IOP.

For some patients, anti-glaucoma medication had to be reintroduced during the study period (Figure 4). In the following calculations, all 24 eyes which underwent additional IOP-lowering procedures and three eyes with missing data are excluded from analysis of IOP and medication count. The average number of substances was significantly reduced from 3.40 preoperatively to 1.34 at 12 months postoperatively, $P<0.001$ (ANOVA with Dunnett's posthoc). Before surgery, 37 cases were treated with oral acetazolamide, at 1-year follow-up only one of these patients remained on this treatment. However, an additional six patients, who were not in need for this preoperatively were in need of oral medication at 12 months.

\section{Subgroup Analysis}

Comparing POAG with PEXG, we found a slightly higher success rate in the former ( $68 \%$ vs $59 \%$ ), but the difference was not statistically significant; Cox proportional hazard ratio $=0.73(95 \% \mathrm{CI}=0.3-1.40), P=0.346$ (Figure 5A). The proportion of complete success was equal in both groups (30\% vs 33\%; Figure 5B and C).

As an exception from standard Mitomycin-C, five patients received subconjunctival 5-Fluorouracil during surgery. None of these cases led to complete success, one resulted in partial success, and four were classified as failure, leading to secondary glaucoma surgery in three of these. (Statistical analysis not performed due to low numbers.)

In addition to the 59 (52\%) pseudophakic patients at baseline, an additional 16 eyes (14\%) became pseudophakic through combined cataract surgery with XEN stent implantation and nine more eyes became pseudophakic later during the study period, in five of these in order to deepen the anterior chamber and free the XEN stents interior lumen from occluding iris tissue (which was 
Table I Demographic Description

\begin{tabular}{|c|c|}
\hline Variable & $N=1 / 3$ \\
\hline Mean age at surgery (years), mean $\pm S D$ & $70.8 \pm 11.8$ \\
\hline \multicolumn{2}{|l|}{ Sex, n (\%) } \\
\hline Men & $53(46.9)$ \\
\hline Women & $60(53.1)$ \\
\hline \multicolumn{2}{|l|}{ Glaucoma type, n (\%) } \\
\hline Primary open-angle & $53(46.9)$ \\
\hline Pseudoexfoliative & $46(40.7)$ \\
\hline Other $^{\mathrm{a}}$ & $14(12.4)$ \\
\hline Mean duration of glaucoma diagnosis (years), mean $\pm S D$ & $9.7 \pm 8.5$ \\
\hline Mean preoperative IOP, $\mathrm{mmHg} \pm \mathrm{SD}$ & $23.8 \pm 6.2$ \\
\hline Pseudophakic, n (\%) & $59(52.2)$ \\
\hline \multicolumn{2}{|l|}{ Individual target IOP and $\leq 20 \%$ IOP reduction, $\mathrm{n}$ (\%) } \\
\hline Failure & 49 \\
\hline Partial success & 24 \\
\hline Complete success & 27 \\
\hline \multicolumn{2}{|l|}{ I5 mmHg target IOP and $\leq 20 \%$ IOP reduction, $\mathrm{n}(\%)$} \\
\hline Failure & 63 \\
\hline Partial success & 16 \\
\hline Complete success & 21 \\
\hline \multicolumn{2}{|l|}{ I $8 \mathrm{mmHg}$ target IOP and $\leq 20 \%$ IOP reduction, $\mathrm{n}(\%)$} \\
\hline Failure & 54 \\
\hline Partial success & 20 \\
\hline Complete success & 26 \\
\hline \multicolumn{2}{|l|}{$2 \mathrm{I} \mathrm{mmHg}$ target IOP and $\leq 20 \%$ IOP reduction, $\mathrm{n}(\%)$} \\
\hline Failure & 47 \\
\hline Partial success & 25 \\
\hline Complete success & 28 \\
\hline
\end{tabular}

Notes: ${ }^{a}$ Including secondary glaucoma after IOL-luxation, iridocyclitis, goniodysplastic glaucoma, previous angle closure glaucoma, venous stasis glaucoma, and pigment dispersion glaucoma.

Abbreviations: IOL, intraocular lens; IOP, intraocular pressure; SD, standard deviation.

successful in four out of five cases). The success rate (complete or partial) in patients undergoing combined phacoemulsification plus XEN stent implantation was $81 \%$, compared to $61 \%$ in patients subjected to a standalone XEN procedure (including both phakic and pseudophakic patients) (Figure 6A-D). However, this difference was not significant; Cox proportional hazard ratio $=2.57$ (95\% CI $=0.79-8.32$ ), $P=0.116$ (Figure 6A). In the pseudophakic group at baseline, we found the largest proportion of failure (42\%), while eyes that became pseudophakic in conjunction with XEN surgery only failed in $19 \%$. However, the difference in success rate between patients undergoing combined phacoemulsification plus XEN stent implantation and patients subjected to stand-alone XEN procedure was not significant $(P=0.115$, chi-square test, Figure 6B-D). The proportion of stent misplacement (see below) in these two groups was similar (20.3 vs $25 \%$ ).

According to the manufacturer's recommendation, the inner portion of the XEN stent should be approximately $1 \mathrm{~mm}$ inside the anterior chamber with good distance to the iris and endothelium, $2 \mathrm{~mm}$ intrasclerally and approximately $3 \mathrm{~mm}$ subconjunctivally with a straight appearance (Figure 7D). In the present data, it was found that if the outer (subconjunctival) part of the stent was curved (Figure 7E) there was a trend of higher failure rate $(45 \%$ vs $29 \%, P=0.682$; chi-square test with Bonferroni correction for multiple comparisons) compared to a straight appearance (Figure 7A-B). Stents with malpositioning (too posteriorly placed, resulting in occlusion by the iris, or stent too long inside or outside the anterior chamber, or too anteriorly positioned, resulting in endothelial contact) had a significantly worse outcome (Figure 7C) compared to correct positioning $(P=0.004)$.

In the present cohort, four surgeons without any prior experience of XEN stent implantation are represented, each performing $11,16,19$, and 67 procedures, respectively. When analyzing the first 30 to the last 30 eyes of the most productive surgeon, a significantly better outcome was found for the last eyes in this subgroup (10\% failure vs $33 \%, P=0.028$, Figure $8 \mathrm{~A}-\mathrm{C}$ ).

In 14 patients, both eyes were operated on on different occasions, see Tables 3 and 4 . No statistical difference in outcome between first and second eyes was observed (Table $4, P=0.695$ ). The outcome of the first eyes surgery had no predictive value for the second eye (Table 4).

\section{Complications}

All postoperative complications and interventions are listed in Table 5. On day 1, 22 eyes (19.5\%) showed an IOP below $5 \mathrm{mmHg}$, on week 1, 14 eyes (12.4\%), and on week 2, only one eye $(0.9 \%)$ had persistent hypotony. All cases of hypotony resolved without surgical intervention. The anterior chamber was described as "shallow" in 12 cases (10.6\%), but never completely obliterated. Choroidal detachment occurred in 11 cases $(9.7 \%)$. Of these, $10(8.8 \%)$ resolved without surgical intervention within 12 - weeks except in one eye, in which the detachment persisted for 2 months before resolving spontaneously. In more severe detachments, cycloplegic eye drops were usually added to the local steroid treatment.

Iris blockage: In ten eyes (8.8\%), iris tissue blocked the inner lumen of the XEN stent. Initial management in all 

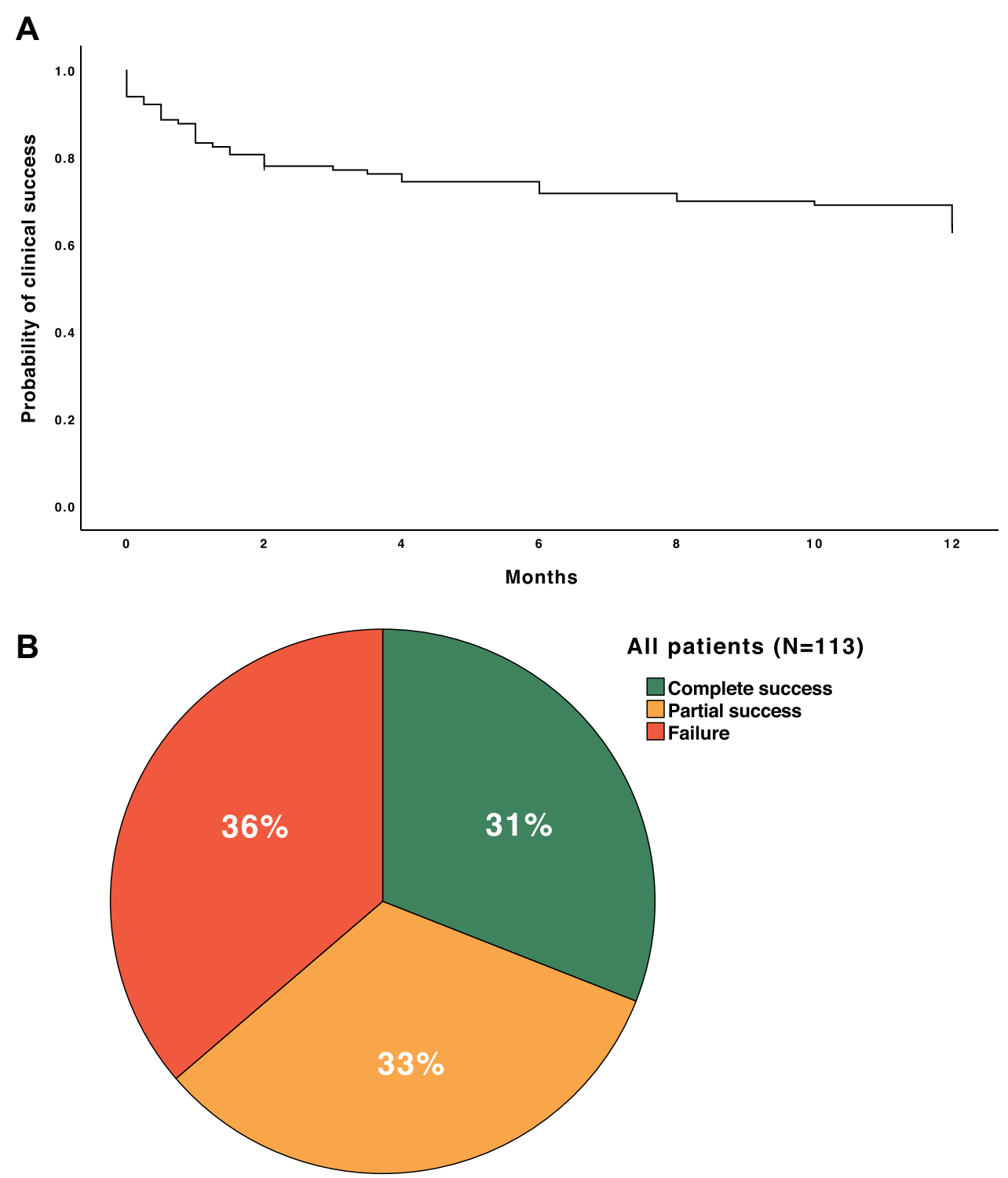

Figure 2 (A) Survival plot based on Kaplan-Meier estimates showing I-year outcome of XEN implantation and probability of clinical success; the remaining cases with complete success (target IOP attained without pharmacologic treatment) and partial success (target IOP attained with the aid of pharmacologic agents). (B) Complete or partial success and failure at I-year follow-up $(\mathrm{N}=|| 3)$.

Abbreviation: IOP, intraocular pressure.

these cases consisted of topical pilocarpine and in some patients, argon laser peripheral iridoplasty (ALPI) and/or Neodymium: YAG iridotomy were also performed. Later, phacoemulsification could be performed if the eye was still phakic. Stent function was restored in some of these cases, leading to complete success in two cases and partial success in another two cases at 12 months. Six eyes were finally judged as failure at 1-year follow-up; three of which had undergone additional glaucoma procedures at that time. In one patient, early stent migration towards the anterior chamber was observed, leading to explantation of the stent due to endothelial contact. Another case of stent migration was observed after some months, in which the stent lost its connection with the anterior chamber entirely, thus ceasing to function.

Needling procedures were performed postoperatively in 49 eyes (43\%), on average 1.78 times/eye. Needling was most common during the first and second month postoperatively. In 30 cases needling was performed once, in seven cases twice, in seven cases three times, in four cases four times, an in one individual seven times during the first 6 months. Needling resulted in $47 \%$ failure, $29 \%$ partial, and $24 \%$ complete success at 1 year after surgery. There was no significant difference 
Table 2 Outcome with Different Intraocular Pressure Targets

\begin{tabular}{|l|l|l|l|}
\hline & $\begin{array}{l}\text { Complete } \\
\text { Success } \\
\text { (\%) }^{\mathbf{a}}\end{array}$ & $\begin{array}{l}\text { Partial } \\
\text { Success } \\
\mathbf{( \% )}^{\mathbf{b}}\end{array}$ & $\begin{array}{l}\text { Failure } \\
\text { (\%) }\end{array}$ \\
\hline Individual Target IOP & 31 & 33 & 36 \\
I5 mmHg target IOP & 23 & 18 & 59 \\
I8 mmHg target IOP & 28 & 25 & 47 \\
$21 \mathrm{mmHg}$ target IOP & 32 & 34 & 35 \\
Individual Target IOP plus & 27 & 24 & 49 \\
$\geq 20 \%$ IOP Reduction & & 16 & 63 \\
I5 mmHg and $\geq 20 \%$ IOP & 21 & 20 & 54 \\
reduction & & 25 & 47 \\
I8 mmHg and $\geq 20 \%$ IOP & 26 & & \\
reduction & & & \\
$21 \mathrm{mmHg}$ and $\geq 20 \%$ IOP & 28 & & \\
reduction & & & \\
\hline
\end{tabular}

Notes: ${ }^{\text {a }}$ Complete success was defined as achieving target pressure at 12 months without medical treatment. ${ }^{b}$ Partial success was defined as achieving target pressure at

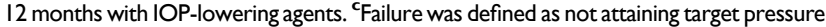
at 12 months with/without pharmacologic treatment or requiring additional IOPlowering surgery or if the XEN stent was non-functioning, ie, broken or without contact with anterior chamber or if visual acuity at 12 months was light perception or worse.

Abbreviation: IOP, intraocular pressure.

in needling rate between XEN stand-alone (44\%) and XEN combined with cataract surgery $(38 \%)$ groups $(P=0.787)$.
No cases of endophthalmitis occurred during the follow-up period. One patient suffered from fibrinous anterior uveitis which resolved without recurrence by treatment with topical steroids. Another patient was lost to followup between month 1-6 postoperatively. When rescheduled, IOP was raised to $67 \mathrm{mmHg}$ and the central visual field was extinguished, classified as XEN failure.

Conjunctival reconstructive surgery was necessary in two eyes due to large subconjunctival Tenon-cysts causing discomfort for the patients. These cases were regarded as XEN failure. As described above, no case of persistent hypotony was observed after 2 months.

\section{Discussion}

This retrospective 1-year follow-up study describes the safety and efficacy of the XEN 45 gel stent at a Swedish tertiary referral center. The mean IOP was reduced by $30 \%$ (paired data) from 22.9 to $16.1 \mathrm{mmHg}$ (excluding individuals who underwent additional glaucoma surgery during the study period). Reitsamer et $\mathrm{al}^{5}$ reported comparable IOP-reduction (-29.3\% at 12 months). The overall clinical success rate (complete or partial success) in our study was

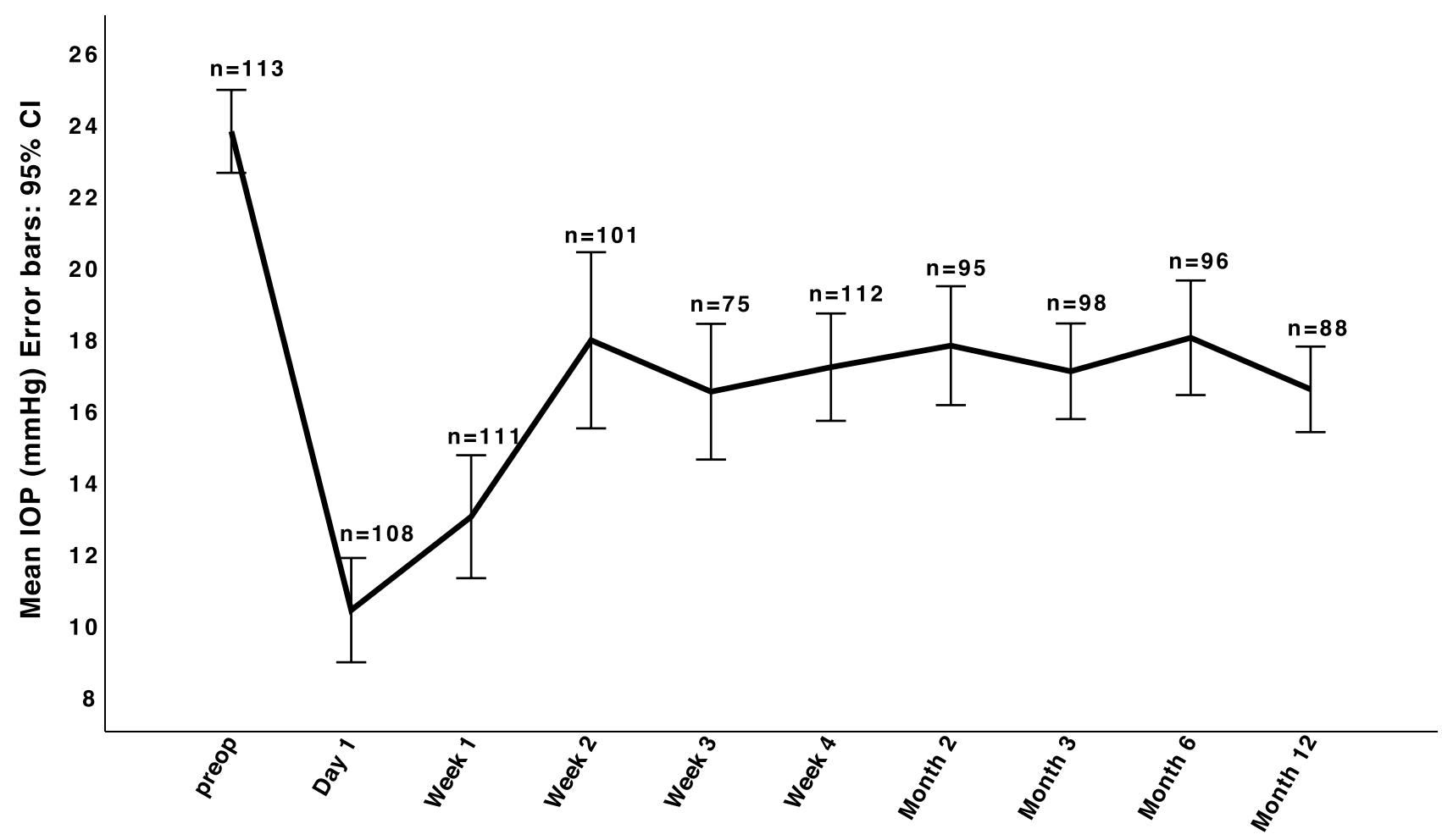

Figure 3 Mean IOP is shown preoperatively and the first postoperative year after XEN implantation. Error bars indicate $95 \% \mathrm{Cl}$. All XEN-patients in the cohort ( $\mathrm{N}=\mathrm{I}$ I 3 at the start of the study period) were included initially. Secondary glaucoma surgery excluded at the time of second surgery.

Abbreviations: $\mathrm{Cl}$, confidence interval; IOP, intraocular pressure. 


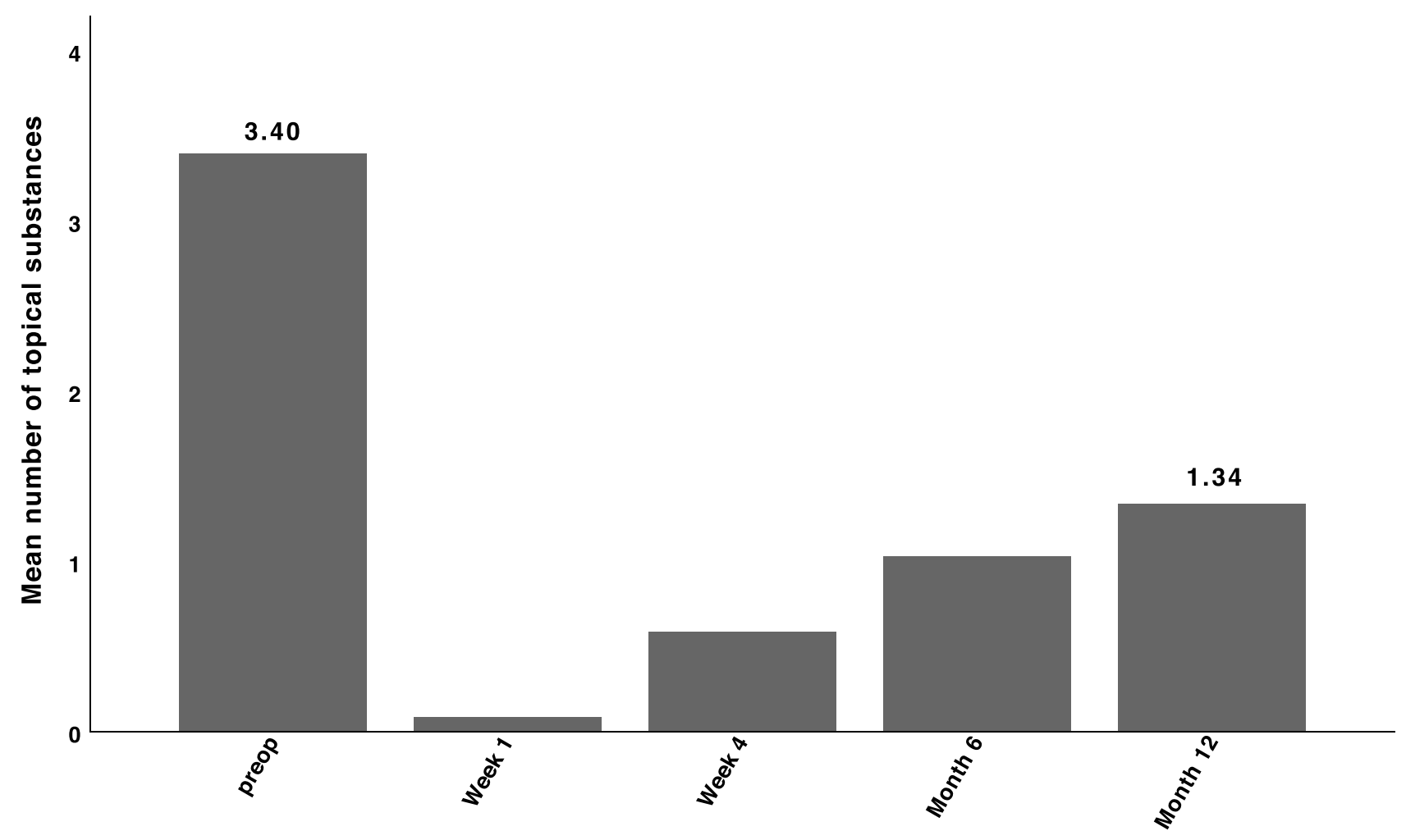

Figure 4 Pharmacologic treatment of glaucoma patients subjected to XEN implantation, showing mean number of topical substances preoperatively and during the first postoperative year. The mean number of pharmacologic substances preoperatively was 3.40, decreasing to I.34 I year after surgery, pP<0.00I (ANOVA with Dunnett's post hoc). Patients with secondary glaucoma surgery were excluded from analysis.

$64 \%$. This is comparable to the 12 -month survival rate of $67 \%$ in the APEX study. ${ }^{5}$

The definition of clinical success is not standardized in the literature. In the present study, success was defined as whether the individual target pressure was attained or not, with (partial success) or without (complete success) the addition of pharmacologic substances. This definition is based on the clinical evaluation found in the medical records, as given by the respective patients' ophthalmologist. As many different referring ophthalmologists were involved, no standardized method or formula for target IOP calculation could be defined for our cohort. Only 12 out of 113 cases had a defined target IOP lower than 20 $\mathrm{mmHg}$. If no individual target pressure was defined in the patient's record, it was set to $20 \mathrm{mmHg}$ in order to avoid definition bias by the author. Lower target pressures would have increased the discrepancy between clinical and study judgment. A definition of success commonly used in studies on glaucoma surgery is a reduction of IOP of at least $20 \%$ from baseline. ${ }^{6}$ However, this type of definition is more suitable in prospective clinical trials where a washout period can be planned before surgery. It is impossible to give the isolated IOP-lowering effect of the XEN stent alone, because of adjustments (often a reduction) of IOP-lowering medication during the study period. However, the IOP reduction described in this study is most likely underestimated, since the average number of IOP-lowering substances was significantly reduced by two substances after surgery. Attaining the target pressure is a better reflection of clinical success than an overall requirement of a $20 \%$ IOP-reduction, especially in patients with intolerance to glaucoma medication (37 documented cases in this cohort, in whom surgery aimed to reduce the number of IOP-lowering agents rather than reducing IOP. In these cases preoperative IOP under pharmacologic treatment and postoperative IOP without IOP-lowering medications may be the same, but the aim of surgery is still achieved. If applying lower target IOP on the present data (Table 2), the proportion of failure would amount to $50-60 \%$ of all cases. This demonstrates that the XEN gel stent is not a surgical option for advanced glaucoma and very low target pressure, which is in accordance with the manufacturers' recommendations. With the given retrospective approach, the present study is not designed to demonstrate if lower IOPs could be accomplished with more intensive medication. 

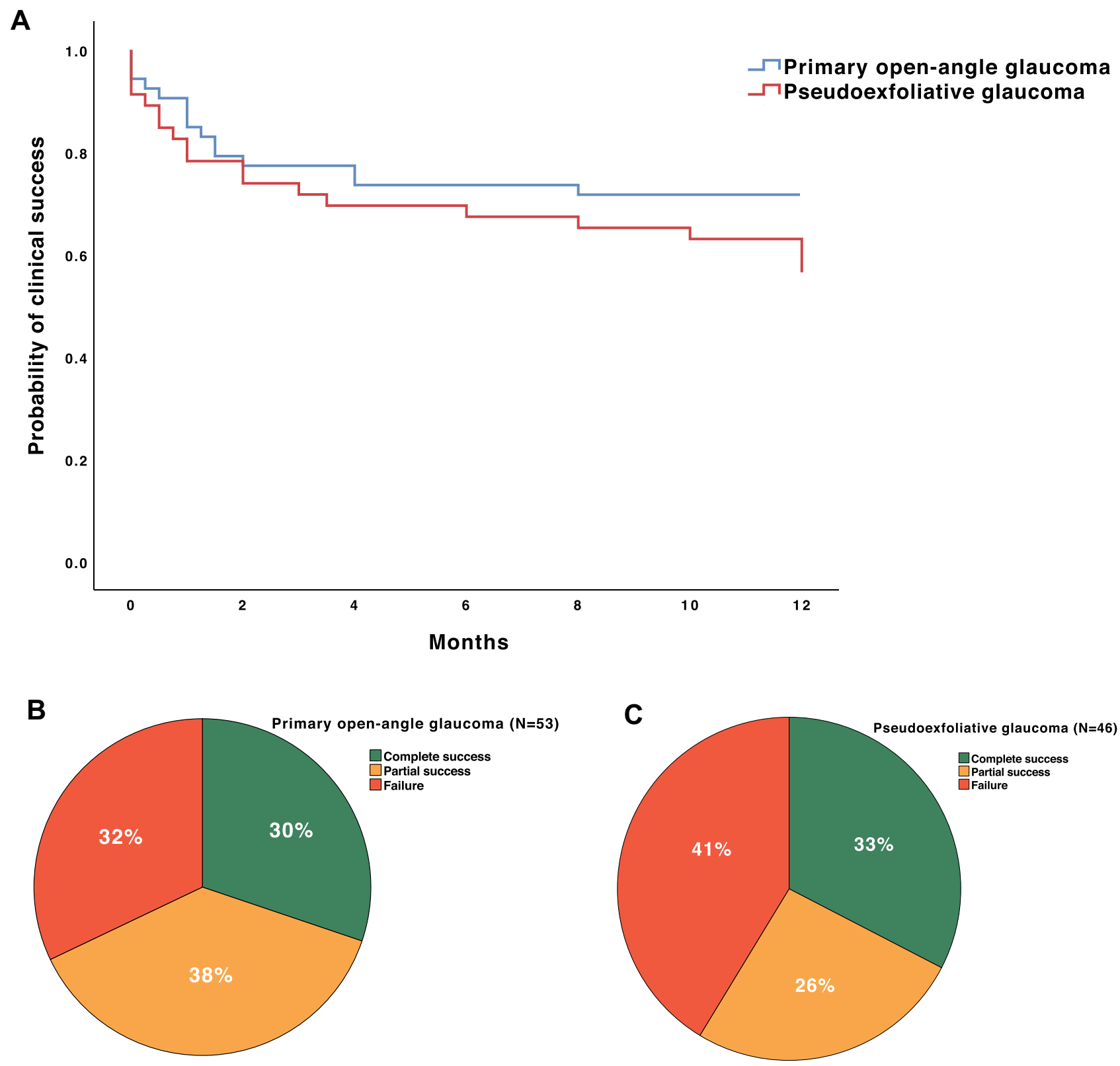

Figure 5 Success of XEN implantation with different types of glaucoma, where complete and partial success are shown during the first postoperative year for patients with primary open-angle glaucoma $(n=53)$ and pseudoexfoliative glaucoma $(n=46)$, respectively. (A) Probability of clinical success; (B) proportions after I year for primary openangle glaucoma; (C) pseudoexfoliative glaucoma.

Notes: No significant difference was seen depending on type of glaucoma; Cox proportional hazard ratio=0.73 $(95 \%$ confidence interval $=0.3-1.40)$, $P=0.346$.

Grover et $\mathrm{al}^{7}$ showed at least $20 \%$ lower IOP on the same or less medication at 12 months after XEN stent implantation in $75.4 \%$ of patients with predominantly POAG. However, the technique for Mitomycin (MMC)-application differed significantly in that study; the conjunctiva was opened surgically, MMC were applied on sponges, and the conjunctiva sutured with Vicryl thereafter. This surgical approach may have influenced the outcome, since subconjunctival adhesions are possibly better dissected by surgical preparation than by hydrodissection as in this study.
In the present study, the mean number of pharmacologic agents decreased in our population from 3.40 preoperatively to 1.34 at 1 year postoperatively. In three eyes $(3.4 \%)$, the number of topical substances was increased compared to pre-surgery, in $20(23.0 \%)$ cases the number of substances was unchanged, while in 64 cases $(73.6 \%)$, treatment was reduced. In Table 6, some of the largest studies so far reporting on outcome of XEN 45 gel stent implantation are summarized with regard to change in IOP-lowering medication. The decrease in pharmacologic 


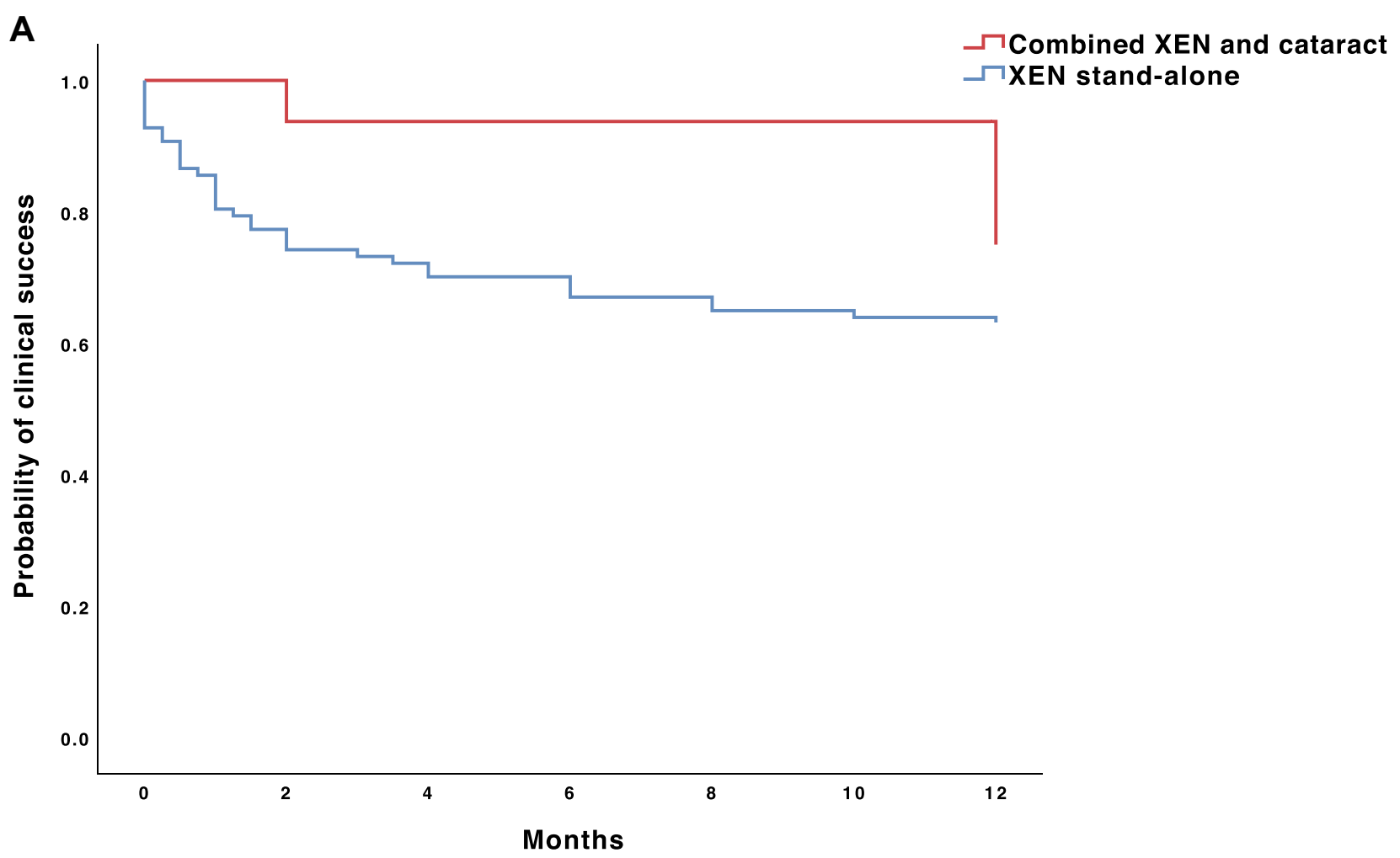

B

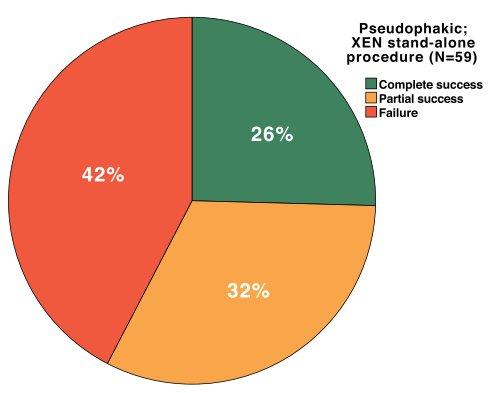

C

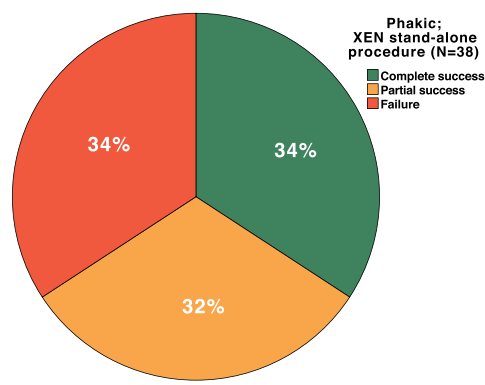

D

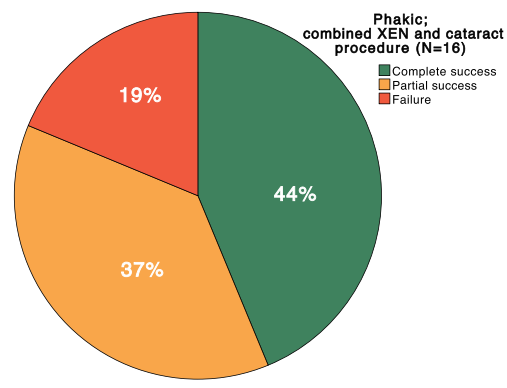

Figure 6 One-year results after XEN gel stent procedure when combined with or without phacoemulsification and intraocular lens implantation. (A) Probability of clinical success; (B) proportions after I year for pseudophakic XEN stand-alone procedures; (C) phakic stand-alone; (D) phakic combined procedures.

Notes: Complete and partial success rate with $(n=16)$ and without $(n=97)$ combined surgery are shown with no significant difference between groups; Cox proportional hazard ratio $=2.57(95 \%$ confidence interval $=0.79-8.32), P=0.116$. The success rate in patients undergoing combined phacoemulsification plus $X E N$ stent implantation was $81 \%$, compared to $61 \%$ in patients subjected to stand-alone XEN procedure (including both phakic and pseudophakic patients), $P=0.115$ (Chi-square test).

treatment observed in the present study is in the same magnitude, ie a reduction of about two substances, as in those previous studies.

The prevalence of pseudoexfoliations is high in Scandinavia; in the Northern part of Sweden it has been reported as high as $61 \%$ in 87 -year-olds. ${ }^{8}$ As a consequence, pseudoexfoliative glaucoma (PEXG) is also common, accounting for $59 \%$ of open-angle glaucoma among elderly people in Northern Sweden. ${ }^{8}$ The proportion of PEXG in our material $(40.7 \%)$ is therefore representative for Scandinavia, but exceptionally high compared to other populations. We found that the XEN
45 gel stent works well also in PEXG. Compared with POAG, there was a slight tendency towards better results in the POAG group, but this was not statistically significant. The present data thus confirms the findings of prospective studies after 1 year ${ }^{9}$ and 2 years, ${ }^{10}$ which did not find any difference between POAG and PEXG.

The needling rate in the present study was $43 \%$. Needling rates and bleb intervention between $32 \%$ and $71 \%{ }^{11}$ have been reported at 12 months by others. ${ }^{12}$ Most of the needling procedures were performed during the first months after surgery, but there are some individual cases where needling was successful even after a longer 
A

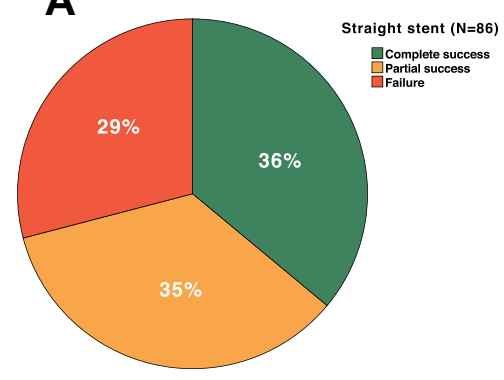

D

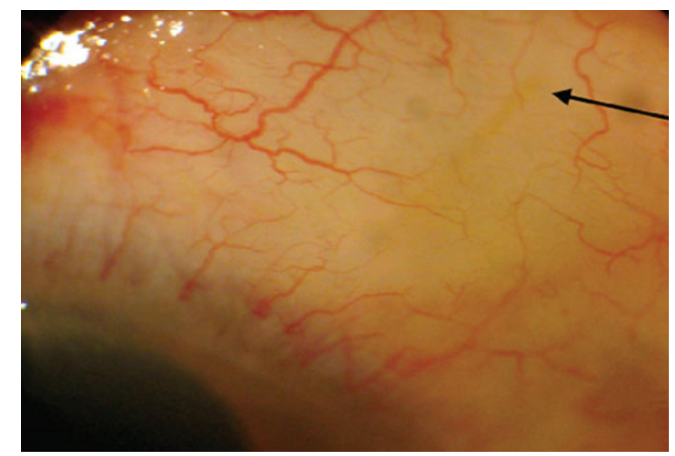

B

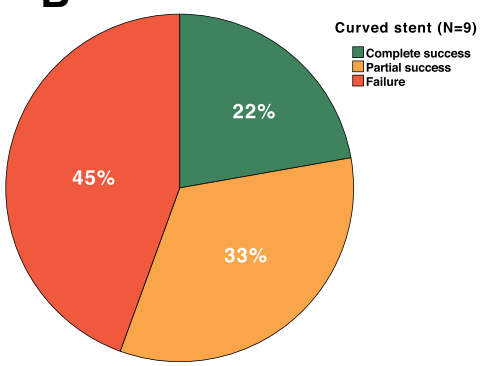

C

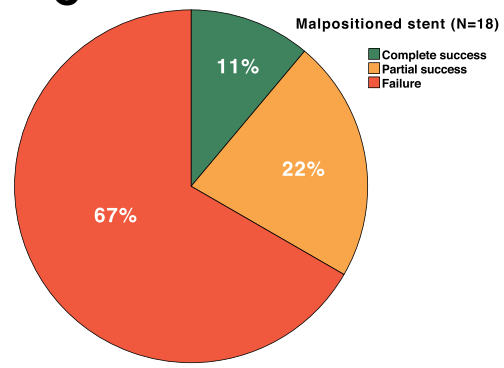

E

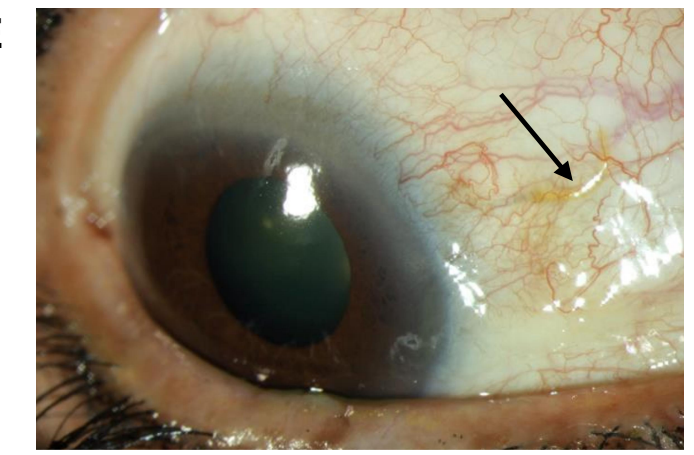

Figure 7 Proportions of complete and partial success and failure at I-year follow-up in patients with (A) straight; (B) curved; (C) malpositioned XEN gel stents. Pictures show (D) perfectly positioned straight XEN gel stent; (E) curved XEN gel stent.

Notes: Malpositioning included lumen blocked by iris $(n=7)$, no connection with anterior chamber $(n=6)$, stent too proximally positioned, ie, too long portion of stent in anterior chamber $(n=4)$, and stent with endothelial contact $(n=1)$. Success rate was significantly worse in the malpositioned group compared to the correct straight group, $P=0.004$ (chi-square test with Bonferroni correction for multiple comparisons) but not in the curved group, $P=0.682$.

A

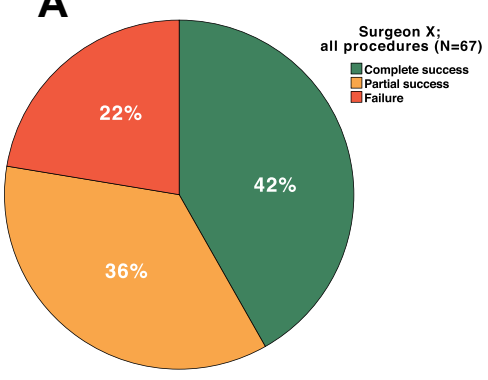

B

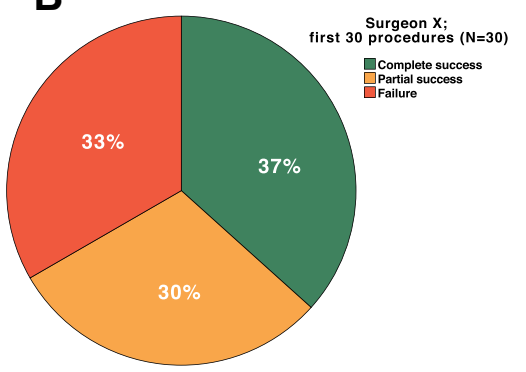

C

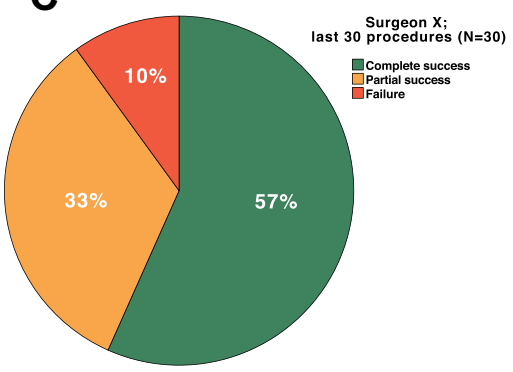

Figure 8 Learning curve for XEN implantation, showing outcome I-year postoperatively for one surgeon (TB) only. (A) Success rate of all patients ( $\mathrm{n}=67$ ) operated on by the same surgeon during the study period is shown; (B) The first 30 procedures were compared to $(\mathbf{C})$ the last 30 procedures, showing a significant improvement in success rate, $p P=0.028$ (Chi-square test).

period. In the 2-year follow-up APEX study, the needling rate the first year $(32.1 \%$, personal communication) increased to $41.1 \%$ at 24 months. Studies with a higher success rate seem to correlate with more aggressive bleb management. ${ }^{12}$ In our hands, needling was used as an intervention against failure mainly during the first postoperative months. Through needling, 53\% of cases could be converted to partial or complete success at 1 year. We believe that there is a learning curve even for the postoperative care in terms of timing and how to perform needling. Recommendations on the management of bleb fibrosis have been published recently. ${ }^{13}$ In case of elevated IOP, steroid response or occlusion of the inner stent lumen have to be ruled out first. During the study period, recommendations on this subject have been modified by the manufacturer. Initially, all types of bleb fibrosis were to be treated by needling. Our current opinion is that highly elevated blebs can be treated by aqueous suppressor drugs such as acetazolamide, while waiting for the inflammatory reaction to calm down and delaying any needling. Completely dry filtrations blebs are to be needled immediately. We routinely combine needling with 
Table 3 Outcome in Bilateral Cases (Surgery on Different Occasions)

\begin{tabular}{|c|c|c|c|c|}
\hline Ist Eye $(n=\mid 4)$ & Individual IOP Target & I 5 mmHg Target IOP & $18 \mathrm{mmHg}$ Target IOP & $21 \mathrm{mmHg}$ Target IOP \\
\hline Complete success, $\mathrm{n}(\%)^{\mathrm{a}}$ & $6(43)$ & $6(43)$ & $6(43)$ & $6(43)$ \\
\hline Partial success, n (\%) & $4(29)$ & $2(14)$ & $3(21)$ & $4(29)$ \\
\hline Failure, $n(\%)^{c}$ & $4(29)$ & $6(43)$ & $5(36)$ & $4(29)$ \\
\hline \multicolumn{5}{|l|}{ 2nd Eye $(n=14)$} \\
\hline Complete success, $\mathrm{n}(\%)^{\mathrm{a}}$ & 4 (29) & $4(29)$ & $4(29)$ & 4 (29) \\
\hline Partial success, $\mathrm{n}(\%)^{\mathbf{b}}$ & $4(29)$ & I (7) & $2(14)$ & $4(29)$ \\
\hline Failure, n (\%) & $6(43)$ & $9(64)$ & $8(57)$ & $6(43)$ \\
\hline
\end{tabular}

Notes: ${ }^{\mathbf{a}}$ Complete success was defined as achieving target pressure at 12 months without medical treatment. ${ }^{\mathbf{b}}$ Partial success was defined as achieving target pressure at 12 months with IOP-lowering agents. ${ }^{c}$ Failure was defined as not attaining target pressure at 12 months with/without pharmacologic treatment or requiring additional IOPlowering surgery or if the XEN stent was non-functioning, ie, broken or without contact with anterior chamber or if visual acuity at $I 2$ months was light perception or worse. Abbreviation: IOP, intraocular pressure.

subconjunctival injection of $0.1 \mathrm{~mL}$ 5-Fluouracil. In the case of incapsulated XEN 45 gel stents, which are not visible in the slit lamp microscope through thickened conjunctiva and tenon, we would consider conjunctival reconstructive surgery with excision of scar tissue in the operating theater and treating the wound with a Mitomycin-soaked sponge. There is no such case in the presented cohort.

The present study is the first to investigate whether or not there is a learning curve for implantation of XEN 45 gel stent. Indeed, a considerable learning curve for XEN implantation was demonstrated, even for very experienced

Table 4 Outcome of Ist and 2nd Eye XEN Stent Implantation in Bilateral Cases

\begin{tabular}{|c|c|c|}
\hline Patient No. & Ist Eye & 2nd Eye \\
\hline I & Complete success ${ }^{a}$ & Complete success \\
\hline 2 & Failure $^{c}$ & Partial success ${ }^{\mathbf{b}}$ \\
\hline 3 & Complete success & Partial success \\
\hline 4 & Failure & Failure \\
\hline 5 & Complete success & Failure \\
\hline 6 & Complete success & Complete success \\
\hline 7 & Failure & Failure \\
\hline 8 & Complete success & Complete success \\
\hline 9 & Partial success & Failure \\
\hline 10 & Partial success & Complete success \\
\hline II & Failure & Partial success \\
\hline 12 & Partial success & Partial success \\
\hline 13 & Complete success & Failure \\
\hline 14 & Partial success & Failure \\
\hline
\end{tabular}

Notes: a Complete success was defined as achieving target pressure at 12 months without medical treatment. ${ }^{b}$ Partial success was defined as achieving target pressure

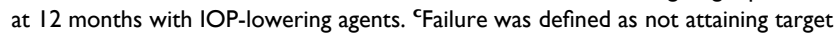
pressure at 12 months with/without pharmacologic treatment or requiring additional IOP-lowering surgery or if the XEN stent was non-functioning, ie, broken or without contact with anterior chamber or if visual acuity at 12 months was light perception or worse. cataract and glaucoma surgeons. The implantation technique itself is easy to perform, but optimal placement of the stent can be challenging and intraoperative need for further manipulation or replacement of the stent may occur. In view of the present data, demonstrating inferior results depending on the positioning of the stent, correct placement of the stent at the time of the initial procedure should be emphasized, and vigorous attempts to adjust the position and to achieve a straight course of the stent are important for success. It may be expected that results of XEN implantation, if surgeons have passed their initial learning curve, ensuring correct positioning of the stent

Table 5 Complications and Interventions

\begin{tabular}{|c|c|c|}
\hline $\begin{array}{l}\text { Complication or } \\
\text { Intervention }\end{array}$ & $\begin{array}{l}\text { Within I } \\
\text { Month, N }\end{array}$ & $\begin{array}{l}\text { Within 2-6 } \\
\text { Months, N }\end{array}$ \\
\hline Hypotony $^{\mathrm{a}}$ & 25 & 0 \\
\hline Choroidal detachment & 11 & $\mathrm{I}^{\mathrm{b}}$ \\
\hline Loss of vision & 0 & I \\
\hline Iris blocking lumen of stent & 10 & 0 \\
\hline $\begin{array}{l}\text { Persisting hemorrhage in } \\
\text { anterior chamber }\end{array}$ & I & 0 \\
\hline Migration of stent & $I^{c}$ & $I^{d}$ \\
\hline Corneal ulcer & 1 & 0 \\
\hline $\begin{array}{l}\text { Conjunctival fistula or } \\
\text { subconjunctival cysts }\end{array}$ & 0 & $3^{e}$ \\
\hline Fibrin in anterior chamber & I & 0 \\
\hline Malignant glaucoma & I & 0 \\
\hline No passage of aqueous & I & 0 \\
\hline Needling required & 0 & $49^{f}$ \\
\hline
\end{tabular}

Notes: ${ }^{a}$ Hypotony was defined as intraocular pressure $<5 \mathrm{mmHg}$. Number of individual cases which had hypotony on at least one occasion. Day I: $n=22$, week $I=I 4$, week $3+4=I$. ${ }^{b}$ One case in whom the choroidal detachment persisted for 2 months. ${ }^{\mathrm{C}}$ This stent was explanted. ${ }^{\mathrm{d}}$ The stent lost contact with anterior chamber. ${ }^{e}$ One case of avascular conjunctiva and two cases of conjunctival cysts. ${ }^{f} \mathrm{Number}$ of eyes where needling was performed. For some patients several needling procedures were required. Mean number of needling procedures were 1.78 per eye. 'Loss of central visual field due to undetected IOP decompensation (lost to follow-up). 
Table 6 Reduction in Pharmacologic Glaucoma Medication - Summary of Studies

\begin{tabular}{|c|c|c|c|c|c|}
\hline Study & $\begin{array}{l}\text { No. of IOP-Lowering } \\
\text { Agents at Baseline }\end{array}$ & $\begin{array}{l}\text { No. of IOP-Lowering } \\
\text { Agents I } 2 \text { Months } \\
\text { Postop }\end{array}$ & $\mathbf{N}$ & Glaucoma Type & Procedure $^{a}$ \\
\hline $\begin{array}{l}\text { De Gregorio et al, }{ }^{15} 2018 \\
\text { Gillmann et al, }{ }^{10} 2019\end{array}$ & $\begin{array}{l}2.5 \\
1.9 \\
2.0\end{array}$ & $\begin{array}{l}0.4 \\
0.6 \\
0.4\end{array}$ & $\begin{array}{l}41 \\
110\end{array}$ & $\begin{array}{l}\text { Mixed cases } \\
\text { POAG } \\
\text { PEXG }\end{array}$ & $\begin{array}{l}\text { Combined } \\
\text { Stand-alone and combined }\end{array}$ \\
\hline Grover et al, ${ }^{7} 2017$ & 3.5 & 1.7 & 65 & Mixed cases & Stand-alone \\
\hline Hengerer et al, ${ }^{16} 2017$ & 3.13 & 0.3 & 242 & Mixed cases & Stand-alone and combined \\
\hline Mansouri et al, ${ }^{9} 2018$ & $\begin{array}{l}1.9 \\
2.0\end{array}$ & $\begin{array}{l}0.4 \\
0.5\end{array}$ & 110 & $\begin{array}{l}\text { POAG } \\
\text { PEXG }\end{array}$ & Stand-alone and combined \\
\hline Tan et al, ${ }^{12} 2018$ & 3.0 & 0.7 & 39 & Mixed cases & Stand-alone \\
\hline Widder et al, ${ }^{17} 2018$ & 2.6 & 0.2 & 233 & Mixed cases & Stand-alone and combined \\
\hline
\end{tabular}

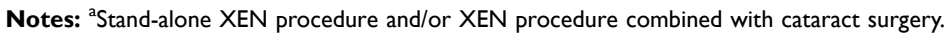

Abbreviations: IOP, intraocular pressure; POAG, primary open angle glaucoma; PEXG, pseudoexfoliative glaucoma.

in relation to the anterior chamber angle (avoiding iris incarceration) and under the conjunctiva (straight, free mobile stent) can be optimized. Gonioscopic guidance may be used to facilitate correct placement. The rate of iris blockage was high in this cohort $(8.8 \%)$, but comparable numbers $(7.7 \%)$ have been reported in the literature. ${ }^{12}$ The risk for this misplacement increases, when gonioscopy is not used routinely, the anterior chamber is overfilled with OVD during XEN implantation and due to XEN injector needle bevel angle: As the XEN 45 stent is injected with the injector needle bevel-up, the final position of the stent will be more posterior than initially intended, as the stent will center at the point where the injector needle first penetrates the angle structures (Figure 9). An experienced XEN surgeon will place the injector more anteriorly, thus avoiding iris incarceration even without use of gonioscopy. The gonioscopy-lens is demanding in handling, as it has to be replaced with a Vera hook while the XEN injector is parked in the trabecular meshwork, before the injector can be advanced through the scleral tissue.

We believe that avoiding perforation of Schlemm's canal and thus minimizing bleeding into the anterior chamber can be beneficious. The best XEN Stent position is between

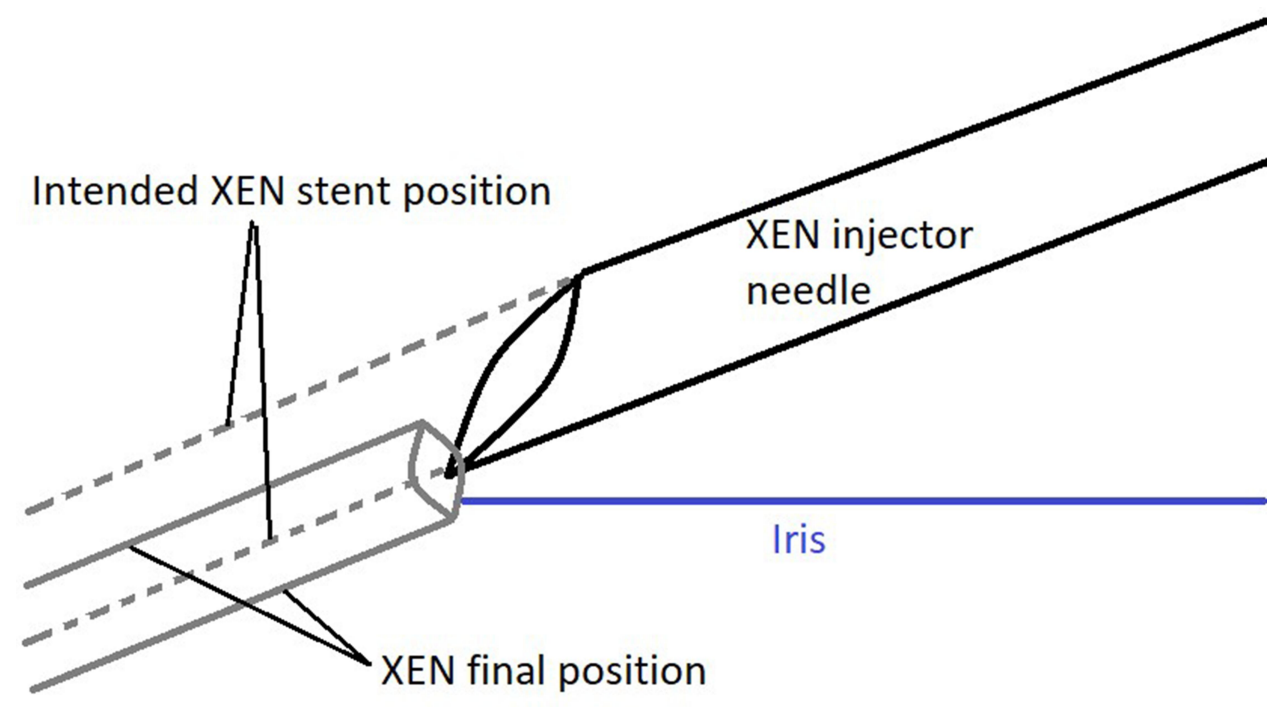

Figure 9 The XEN stent will reach a more posterior final position than the injector needle, since the stent will center around the point where the tip of the needle first penetrates the anterior chamber angle structures. 
Schwalbe's line and through the unpigmented anterior portion of the trabecular meshwork. ${ }^{13}$ A mispositioned stent should be replaced immediately, as documented by Grover et $\mathrm{al}^{7}{ }^{7}$ with one or two replacements in $13.8 \%$ of their surgeries.

Even postoperative handling has a learning curve. Needling procedures can be challenging due to hypervascularity near the XEN 45 gel stent, movement of patient, opaque thickened tissue, and high tissue resistance. Needling maneuvers can be improved by use of a speculum, horizontal patient positioning, foot-pedalmaneuvered microscope, customized bending of an appropriate needle $(27 \mathrm{G})$ or angled lance, use of viscoelastic devices to expand the subconjunctival space and displace occasional bleeding, and repeated application of antimetabolite, eg, 5-fluorouracil.

The outcome of combined cataract surgery and XEN implantation did not show inferior results in the present study. On the contrary, there was a trend towards even better results for combined procedures, but the proportion of cases with combined surgery was too low to reach significance. An IOP-lowering effect of cataract surgery in itself has been demonstrated previously. ${ }^{14}$ In several cases in this study, patients were subjected to cataract surgery during the follow-up period because the iris was assessed as occluding the inner lumen of the stent. Given the fast and relatively non-traumatic procedure of XEN implantation, it is attractive to combine with phacoemulsification in previously phakic patients, thereby avoiding obliteration of the stent and/or new conjunctival adherences due to postoperative inflammation if cataract surgery was to be performed at a later time point. This is in contrast to combined cataract and trabeculectomy, which together may constitute a major trauma for already vulnerable glaucomatous eyes. Reitsamer et $\mathrm{al}^{5}$ found no difference between XEN stand-alone vs XEN combined with phacoemulsification. In contrast, Mansouri et al ${ }^{9}$ found a higher proportion of success in the XEN stent standalone-group compared to combined surgery.

The limitations of this study are its retrospective design and variations in management due to slight differences in strategies between the four surgeons included in the study. The variations include intraoperative management, ie, administration of different antimetabolites, but mainly postoperatively, with variations concerning dosage and duration of topical steroid treatment and different needling strategies. All four surgeons involved were unexperienced at the beginning of the study period and optimized their technique to a certain degree over time, which also resulted in variations over time. After the initial follow-ups during the first 2-3 months postoperatively, follow-ups were performed by nonsurgical glaucoma specialists, further increasing the variability in management. The strengths of the study include a relatively large cohort, a real-world clinical setting with mixed types of cases including a large proportion of PEXG patients. In addition, the present study reports on several important issues that should have major importance for the outcome of XEN 45 gel stent, such as lens status/combined surgery and the importance of correct positioning of the stent. It is also, to our knowledge, the first study demonstrating a learning curve for XEN implantation.

\section{Conclusion}

The XEN 45 gel stent offers a surgical treatment option in refractory glaucoma which is minimally invasive and with a shorter surgical time and less intraoperative discomfort for the patient compared to trabeculectomy. It offers creation of subconjunctival filtration comparable with the working mechanism of traditional trabeculectomy with less surgical manipulation of tissues and no risk for late/persistent hypotony. It can be performed as a stand-alone procedure or combined with phacoemulsification. It is effective in lowering IOP and reducing the number of medications for the majority of patients. However, one third of all cases was considered a failure 1 year after surgery, resulting in the need for additional surgical interventions. If very low target IOPs are to be achieved, the XEN 45 gel stent might not be the first choice. The need for postoperative manipulations, such as needling, is considerable. Bleb management requires experience in filtrating glaucoma procedures. Results are dependent on the experience of the surgeon and may thus be improved by training. The long-time stability of results and cost-effectiveness are still to be proven.

\section{Funding}

The study was financed by grants from the Swedish state under the agreement between the Swedish government and the county councils, the ALF-agreement (ALF-GBG -725041), Göteborg Medical Society, Dr Reinhard Marcuses Foundation, Konung Gustaf V:s och Drottning Victorias Frimurarestiftelse, Hjalmar Svensson Foundation, Greta Andersson Foundation, Herman Svensson Foundation, De Blindas Vänner and Kronprinsessan Margaretas Arbetsnämnd för Synskadade. 


\section{Disclosure}

None of the authors has a financial or proprietary interest in any material or method mentioned. $\mathrm{TB}$ and $\mathrm{AB}$ have received lecture fees and travel expenses from Allergan Inc. The authors report no other potential conflicts of interest for this work.

\section{References}

1. Caprioli J, Kim JH, Friedman DS, et al. Special commentary: supporting innovation for safe and effective minimally invasive glaucoma surgery: summary of a joint meeting of the American Glaucoma Society and the Food and Drug Administration, Washington, DC, February 26, 2014. Ophthalmology. 2015;122(9):1795-1801. doi:10.1016/j.ophtha.2015.02.029

2. Buffault J, Baudouin C, Labbe A. XEN((R)) Gel Stent for management of chronic open angle glaucoma: a review of the literature. $\mathrm{J} \mathrm{Fr}$ Ophtalmol. 2019;42(2):e37-e46. doi:10.1016/j.jfo.2018.12.002

3. Fernandez-Garcia A, Zhou Y, Garcia-Alonso M, Andrango HD, Poyales F, Garzon N. Comparing medium-term clinical outcomes following $\mathrm{XEN}(\mathrm{R}) \quad 45$ and $\mathrm{XEN}(\mathrm{R}) 63$ device implantation. J Ophthalmol. 2020;2020:4796548. doi:10.1155/2020/4796548

4. Lavin-Dapena C, Cordero-Ros R, D'Anna O, Mogollon I. XEN 63 gel stent device in glaucoma surgery: a 5-years follow-up prospective study. Eur J Ophthalmol. 2020;1120672120952033.

5. Reitsamer H, Sng C, Vera V, et al. Two-year results of a multicenter study of the $a b$ interno gelatin implant in medically uncontrolled primary open-angle glaucoma. Graefes Arch Clin Exp Ophthalmol. 2019;257(5):983-996. doi:10.1007/s00417-019-04251-z

6. Kirwan JF, Lockwood AJ, Shah P, et al. Trabeculectomy in the $21 \mathrm{st}$ century: a multicenter analysis. Ophthalmology. 2013;120 (12):2532-2539. doi:10.1016/j.ophtha.2013.07.049

7. Grover DS, Flynn WJ, Bashford KP, et al. Performance and safety of a new ab interno gelatin stent in refractory glaucoma at 12 months. $\mathrm{Am}$ J Ophthalmol. 2017;183:25-36. doi:10.1016/j.ajo.2017.07.023

8. Astrom S, Stenlund H, Linden C. Incidence and prevalence of pseudoexfoliations and open-angle glaucoma in northern Sweden: II. Results after 21 years of follow-up. Acta Ophthalmol Scand. 2007;85 (8):832-837. doi:10.1111/j.1600-0420.2007.00980.x
9. Mansouri K, Gillmann K, Rao HL, Guidotti J, Mermoud A Prospective evaluation of XEN gel implant in eyes with pseudoexfoliative glaucoma. J Glaucoma. 2018;27(10):869-873. doi:10.1097/ IJG.0000000000001045

10. Gillmann K, Bravetti GE, Mermoud A, Rao HL, Mansouri K. XEN gel stent in pseudoexfoliative glaucoma: two-year results of a prospective evaluation. J Glaucoma. 2019;28(8):676-684. doi:10.1097/IJG.000000 0000001295

11. Lenzhofer M, Strohmaier C, Sperl P, et al. Effect of the outer stent position on efficacy after minimally invasive transscleral glaucoma gel stent implantation. Acta Ophthalmol. 2019;97(8):e1105-e1111. doi:10.1111/aos.14167

12. Tan SZ, Walkden A, Au L. One-year result of XEN45 implant for glaucoma: efficacy, safety, and postoperative management. Eye (Lond). 2018;32(2):324-332. doi:10.1038/eye.2017.162

13. Vera V, Sheybani A, Lindfield D, Stalmans I, Ahmed IIK. Recommendations for the management of elevated intraocular pressure due to bleb fibrosis after XEN gel stent implantation. Clin Ophthalmol. 2019;13:685-694. doi:10.2147/OPTH.S195457

14. Zetterstrom C, Behndig A, Kugelberg M, Montan P, Lundstrom M. Changes in intraocular pressure after cataract surgery: analysis of the Swedish National Cataract Register Data. J Cataract Refract Surg. 2015;41(8):1725-1729. doi:10.1016/j.jcrs.2014.12.054

15. De Gregorio A, Pedrotti E, Russo L, Morselli S. Minimally invasive combined glaucoma and cataract surgery: clinical results of the smallest ab interno gel stent. Int Ophthalmol. 2018;38(3):1129-1134. doi:10.1007/s10792-017-0571-x

16. Hengerer FH, Kohnen T, Mueller M, Conrad-Hengerer I. Ab interno gel implant for the treatment of glaucoma patients with or without prior glaucoma surgery: 1-year results. J Glaucoma. 2017;26 (12):1130-1136. doi:10.1097/IJG.0000000000000803

17. Widder RA, Dietlein TS, Dinslage S, Kuhnrich P, Rennings C, Rossler G. The XEN45 gel stent as a minimally invasive procedure in glaucoma surgery: success rates, risk profile, and rates of re-surgery after 261 surgeries. Graefes Arch Clin Exp Ophthalmol. 2018;256(4):765-771. doi:10.1007/s00417-018-3899-7
Clinical Ophthalmology

\section{Publish your work in this journal}

Clinical Ophthalmology is an international, peer-reviewed journal covering all subspecialties within ophthalmology. Key topics include: Optometry; Visual science; Pharmacology and drug therapy in eye diseases; Basic Sciences; Primary and Secondary eye care; Patient Safety and Quality of Care Improvements. This journal is indexed on PubMed

\section{Dovepress}

Central and CAS, and is the official journal of The Society of Clinical Ophthalmology (SCO). The manuscript management system is completely online and includes a very quick and fair peer-review system, which is all easy to use. Visit http://www.dovepress.com/ testimonials.php to read real quotes from published authors. 